Canadian Journal of Civil Engineering

Canadian

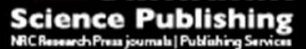

Revue canadienne de génie civil

\title{
Hydrodynamics of Submerged Vegetated Alluvial Channel with Downward Seepage
}

\begin{tabular}{|r|l|}
\hline Journal: & Canadian Journal of Civil Engineering \\
\hline Manuscript ID & cjce-2016-0168.R2 \\
\hline Manuscript Type: & Article \\
\hline Date Submitted by the Author: & 01-Dec-2016 \\
\hline Complete List of Authors: & $\begin{array}{l}\text { Devi, Thokchom; Indian Institute of Technology, Guwahati, } \\
\text { Kumar, Bimlesh; bimk@iitg.ernet.in, civil Engineeering; Indian Institute of } \\
\text { Technology, Guwahati, }\end{array}$ \\
\hline Keyword: & Drag coefficient, Integral scales, submerged vegetation, seepage \\
\hline \multicolumn{2}{|c}{} \\
\hline
\end{tabular}

SCHOLARONE ${ }^{\text {IM }}$

Manuscripts 
Hydrodynamics of Submerged Vegetated Alluvial Channel with Downward Seepage

1. Thokchom Bebina Devi

Research Scholar, Department of Civil Engineering, Indian Institute of Technology Guwahati, Guwahati-781039, India. thokchom@iitg.ernet.in

2. Bimlesh Kumar (Corresponding author)

Associate Professor, Department of Civil Engineering, Indian Institute of Technology Guwahati, Guwahati-781039, India. bimk@iitg.ernet.in, 0091-3612582420 


\begin{abstract}
The flow conditions in a channel covered with fully submerged Oryza sativa has been investigated considering downward seepage. The flow measurements taken at the upstream free vegetation zone, centre of the vegetation zone and downstream free vegetation zone will provide a better understanding regarding the flow hydrodynamics in a vegetated channel. The flow velocity, Reynolds stress and turbulent intensities are reduced at the downstream vegetated section. Downward seepage increases the occurrence of streamwise flux along the length of the channel and vertical flux in the vertically downward direction. Integral length and time scales increase as the percentage of downward seepage increases.
\end{abstract}

Keywords: Drag coefficient, Integral scales, submerged vegetation, seepage 


\section{Introduction}

The presence of vegetation in river channels has a wide range of scientific and engineering implications. Recent investigations stated the importance of aquatic vegetation in improving water quality (Wilcock et al. 1999; Schulz et al. 2003), promoting habitat diversity (Kemp et al. 2000; Crowder and Diplas 2002), alleviating the river bed and channel structures (Braudrick et al. 2009; Chao et al. 2009; Li and Millar 2010) and promoting sediment deposition (Abt et al. 1994; Lopez and Garcia 1998; Cotton et al. 2006; Gurnell et al. 2006). During the last few decades, there has been a great deal of studies employing various approaches for predicting velocity distribution and turbulence properties, and hence overall hydraulic resistance. Nepf and co-workers conducted experimental studies and concluded that vegetation characteristics play an important role in influencing the turbulent structure (Nepf 1999; Finnigan 2000; Finnigan et al. 2009; Nepf 2012). Ghisalberti and Nepf (2006) conducted a series of flume experiments with rigid and flexible vegetation for studying the structure of coherent vortices and vertical transport in shallow vegetated shear flows. Nepf and Vivoni (2000) carried out an experimental study to study the importance of relative submergence depth on turbulence structure. Termini (2015) experimentally investigated that flow submergence affects the mechanism of momentum transfer between the vegetation layer and the layer above it. Wilson et al. (2003) observed that additional superficial area of the fronds influences the momentum exchange between the vegetation layer and the upper flow layer. Yagci and Kabdasli (2008) experimentally investigated the influence of different characteristics of natural vegetation on velocity and turbulence characteristics and found that the presence of vegetation disrupts the flow and dissipates a notable 
amount of energy. Chen et al. (2011) classified the flow in a channel with submerged flexible vegetation into three regions: upper non-vegetated region, middle vegetated layer and lower sheath layer. In addition, previous studies show that vegetation is often found in patches of finite length and width, rather than continuous segments (Sand-Jensen and Madsen 1992; Naden et al. 2006; Temmerman et al. 2007; Schoelynck et al. 2012), and therefore recent attention has been focusing on the study of finite patches of vegetation, both in the laboratory and in the field (Cotton et al., 2006; Bouma et al., 2009; Zong and Nepf 2011; Chen et al. 2012). Siniscalchoi et al. (2012) investigated the effects of a finite-size vegetation patch and found that Reynolds stresses found within the vegetation zone affects the shape of the longitudinal velocity profile and associated turbulent fluxes. Consequently, it is important to consider the bed condition of a mobile channel. A mobile bed channel are formed with permeable sediment particles as in natural rivers and irrigation channels. Therefore, the difference in the water level in the channel and groundwater table will allow water to seep in or out of the channel. Different investigations assessed that seepage losses can account for about $15 \%-50 \%$ of the total flow volume in canals (Tanji and Kielen 2002; Kinzli et al. 2010; Martin and Gates 2014). Besides seepage losses, the presence of downward seepage changes the hydrodynamic behaviour of the channel (Richardson et al. 1985; Maclean 1991; Rao et al. 1994; Chen and Chiew 2004; Deshpande and Kumar 2015, Patel et. al. 2015).

There is a need to investigate the flow characteristics in a seepage affected vegetated channel. Recent investigations (Devi and Kumar 2015; Devi et al. 2016; Devi and Kumar 2016a; Devi and Kumar 2016b) investigated the effect of downward seepage in a vegetative channel using artificial vegetation cylinders. However, the main goal of the 
present study is to explore the interactions between a permeable channel and fully covered natural vegetation of finite length. The effect of downward seepage on different flow conditions has been investigated by conducting experiments.

\section{Experimentation}

Experiments were conducted in a tilting flume of $20 \mathrm{~m}$ in length, $1 \mathrm{~m}$ in width, and 0.72 $m$ deep with special provision for downward seepage. Details of the experimental set up can be found in Devi and Kumar 2015, Devi et al. 2016 and Devi and Kumar 2016a.

\section{Insert Figure 1}

Existing literature on vegetation (Järvelä 2005; Poggi et al. 2004; Ghisalberti and Nepf 2006; Liu et al. 2008) did not provide any specific condition for fixing the flow depth, therefore, the present study fixed the flow depth according to incipient motion for a particular sand diameter, $d_{50}=0.418 \mathrm{~mm}$. The flow depth $(H)$ was found to be $12 \mathrm{~cm}$ at the centre of the test section according to Yalin's incipient motion criteria (1972) and verified with Shields diagram. The flow Reynolds number was $1.3 \times 10^{5}$ and flow Froude number was 0.25 . The test section was located in the middle of the flume covering an area of $5 \mathrm{~m}$ long and $0.5 \mathrm{~m}$ wide where natural rice stems (Oryza sativa) were planted for the whole test section at a vegetation density of $560 \mathrm{stems} / \mathrm{m}^{2}$ to simulate a fully submerged canopy. The height of the vegetation $\left(h_{v}\right)$ was $4 \mathrm{~cm}$ and the deflected vegetation height occurred in the range of $3-3.5 \mathrm{~cm}$ (average deflected vegetation height, $\left.h_{v d}=3.25 \mathrm{~cm}\right)$.

The aggregate stiffness, as defined by Kouwen and Unny (1973) and Kouwen and Li (1980) was observed to be $3.58 \times 10^{-4} \mathrm{Nm}^{2}$. The motion of a flexible vegetation can be classified as erect, gently swaying without organized motions, monami with organized 
motions and prone (Carollo 2005; Okamoto and Nezu 2009). The vegetation for the particular study did not show prone configuration as found out by equation developed by Kouwen and $\mathrm{Li}$ (1980). The flow pattern in the present study was gently swaying according to Okamoto and Nezu (2010).

Flow measurements taken at the upstream section, centre of the vegetation section and downstream section will help in studying the distribution of flow characteristics along the channel length. Zeng and Li (2014) developed an empirical equation for calculating the fully developed flow conditions by finding out a parameter, adjustment length, beyond which uniform flow condition is reached. The empirical equation proposed by Zeng and Li (2014) for mean velocity:

$$
L_{u}=1.5 \frac{U_{a v}}{\sqrt{-\left(u^{\prime} w^{\prime}\right)_{\max }}} H
$$

Where $L_{u}$ is the adjustment length, $U_{a v}$ is the mean velocity, $H$ is the flow depth and $-\left(u^{\prime} w^{\prime}\right)_{\max }$ is the peak Reynolds stress per unit mass. The adjustment lengths for no seepage, $10 \%$ seepage and $15 \%$ seepage are $1.99 \mathrm{~m}, 1.88 \mathrm{~m}$ and $1.83 \mathrm{~m}$ which implies that fully developed flow conditions were achieved before the measurement location. The uncertainty of Vectrino data can be found in Devi and Kumar (2016a).

\section{Insert Table 1}

For data collection, SNR was fixed at 15 or above and the signal correlation between transmitted and received signals of $70 \%$ was recommended as cut-off value (Deshpande and Kumar 2016). Post-processing of the velocity data collected by ADV was needed as there was formation of spikes in the raw data. These spikes were cleared out by acceleration thresholding method (Goring and Nikora 2002). 


\section{Results}

The transition from sand bed to the vegetated bed leads to the development of a new boundary layer. Figure 3 shows the distribution of velocity (streamwise) at the free upstream ( $0.5 \mathrm{~m}$ upstream of the vegetation zone), centre (centre of the vegetation zone) and free downstream $(0.5 \mathrm{~m}$ downstream of the vegetation zone $)$ sections. The flow velocity (no seepage) in the free upstream of the vegetation zone follows a logarithmic velocity profile (Figure 2) as observed by Chen and Chiew (2004). For fitting the data points in the inner layer to the logarithmic law of the wall, the time averaged velocity, $U$ and the vertical distance, $z$ are scaled by the shear velocity, $u *$ and $d_{50}$ such that $u^{+}=U / u_{*}$ and $z^{+}=z / d_{50}$. More detail information regarding the fitting can be found in Deshpande and Kumar (2016). The fitting of the log law is shown in Figure 2. The non-dimensional expression of the log law is:

$$
\frac{U}{u_{*}}=\frac{1}{k} \ln \left(\frac{z^{+}+\Delta z^{+}}{\chi^{+}}\right)
$$

where $z^{+}=z / d_{50}, \Delta z^{+}=\Delta z / d_{50}, \Delta z$ is the depth of the virtual bed below the bed surface, $\chi^{+}=z_{0} / d_{50}, z_{0}$ is the zero velocity level and $k$ is the von Karman's coefficient. The calculation of these parameters are explained in Dey et al. (2012). The values of von Karman's coefficient are $0.41,0.37$ and 0.36 for no seepage, $10 \%$ seepage and $15 \%$ seepage respectively. The value of von Karman's coefficient for no seepage condition matches well with the universal value (0.40). The presence of downward seepage leads to more sediment transport in the channel thereby achieving a lower value of von Karman's coefficient. The depth of virtual bed level and zero velocity level for no seepage are 2.92 $\mathrm{mm}$ and $0.04 \mathrm{~mm} ; 4.18 \mathrm{~mm}$ and $0.13 \mathrm{~mm}$ for $10 \%$ seepage and $5.85 \mathrm{~mm}$ and $0.69 \mathrm{~mm}$ for 
$15 \%$ seepage. The increase in the value of virtual bed level and zero velocity level with increase in the percentage of downward seepage is synonymous to the exposure of sediment particles on the bed surface to an increased velocity. The velocity profile shows similar trend as observed by Righetti (2008), Chen et al. (2011) and Li et al. (2014). Velocity is decreased in the region close to the top of the vegetation, dividing the flow region into two main regions. Figure 3 shows that flow is fully developed in the flow region above the vegetation and decreases toward the vegetation region. The resistance offered by the vegetation patch reduces the flow velocity in the lower vegetation layer. Downward seepage changes the flow discharge and momentum transfer thereby modifying the velocity profile. As reported by previous investigations on downward seepage, the velocity profile shifts downwards (Chen and Chiew 2004; Cao and Chiew 2013). From figure 3, an increase in the flow velocity with increase in downward seepage percentage is noted.

[Insert Figure 2]

[Insert Figure 3]

\section{Reynolds Stresses}

The occurrence of maximum Reynolds stress is different for upstream free vegetation zone and centre of the vegetation zone. The occurrence of maximum value of Reynolds stress close to the bed for upstream free vegetation zone shows that main turbulence production comes from the channel bed while it is not the same for vegetation zone. A shear layer is formed because of the momentum exchange close to the top of the vegetation. Oscillations are produced near the top of the vegetation because of the shear layer. These oscillations exchanges the momentum between the vegetated layer and 
surface layer leading to the formation of maximum Reynolds stress at this region. Figure 4 shows different distributions of Reynolds stress at upstream, centre and downstream of vegetation zone. The distribution of Reynolds stress shows that maximum value occurs near the vegetation top and then decreases towards the bed. The decrease in the Reynolds stress towards the bed is because of the fact that the momentum exchange between the flow layers are obstructed by vegetation. Local erosion and deposition occur around the vegetation in the vegetation zone and therefore a higher value in the Reynolds stress is achieved. Another noteworthy point is the occurrence of negative Reynolds stress near the channel bed. The occurrence of this negative Reynolds stress is accredited to the dominance of turbulent transport of stress over pressure velocity gradient as explained by Shaw (1977).

[Insert Figure 4]

The presence of downward seepage modifies the flow velocity, having more velocity in the region close to the bed thereby affecting the boundary shear stresses. Previous studies on downward seepage (Maclean 1991; Rao et al. 1994; Chen and Chiew 2004; Deshpande and Kumar 2015; Patel et. al. 2015) found that downward seepage elevates the bed shear stress and therefore promoting bed material transport. Downward seepage elevates the maximum Reynolds stress at no seepage by a percentage increase of $19 \%$ (average) for $10 \%$ seepage and $38 \%$ (average) for $15 \%$ seepage. The most interesting finding of this study is that vegetation acts as a mattress for reducing erosion by achieving a reduced value of Reynolds stress at the downstream vegetated section (average value of $15 \%$ ).

\section{RMS of turbulent velocity fluctuations}


One of the most important characteristics for studying turbulence is the degree of turbulent fluctuations present in a turbulent flow. The velocity fluctuations present in a turbulent flow is represented in the form of root mean square. It is defined as:

$$
\begin{gathered}
\sigma_{u}=\sqrt{\frac{\sum_{i=1}^{n}\left(u_{i}-U\right)}{n}} \\
\sigma_{w}=\sqrt{\frac{\sum_{i=1}^{n}\left(w_{i}-W\right)}{n}}
\end{gathered}
$$

\section{[Insert Figure 5]}

The centre and downstream of the vegetation zone have a maximum value of RMS of turbulent velocity fluctuations near the top of the vegetation while the upstream freevegetation zone achieves a maximum value close to the bed (Figure 5). The presence of shear layer close to the top of the vegetation leads to production of more turbulent fluctuations and therefore achieves a maximum value near the top of the vegetation. The trend of RMS of turbulent velocity fluctuations in vertical direction is similar to the longitudinal RMS of turbulent velocity fluctuations with the only difference in magnitude where RMS of longitudinal turbulent velocity fluctuations are nearly three times the RMS of vertical turbulent velocity fluctuations. With the application of downward seepage, the shear stress is increased from no seepage to $10 \%$ seepage and from $10 \%$ seepage to $15 \%$ seepage. This implies that the RMS of turbulent fluctuations is increased. The RMS of turbulent velocity fluctuations increases by a value of $16 \%$ for $10 \%$ seepage and $27 \%$ for $15 \%$ seepage as compared to no-seepage case.

\section{Moment Analysis}


The third order correlation of velocity fluctuations, defined by $M_{j k}=\overline{\hat{u}^{j} \hat{w}^{k}}$ where $\mathrm{j}+\mathrm{k}=3$, $\hat{u}=u^{\prime} /\left(\overline{u^{\prime} u^{\prime}}\right)^{0.5}$ and $\hat{w}=w^{\prime} /\left(\overline{w^{\prime} w^{\prime}}\right)^{0.5}$ (Raupach 1981), gives information on contribution of velocity fluctuations by flux and diffusion to the turbulent coherent structures. $M_{30}$ $\left(\overline{\hat{u}^{3}}\right)$ defines the streamwise flux of the streamwise Reynolds normal stress while $M_{03}$ shows the vertical flux of the vertical Reynolds normal stress. $M_{12}\left(\overline{\hat{u}^{1} \hat{w}^{2}}\right)$ and $M_{21}$ $\overline{\left(\hat{u}^{2} \hat{w}^{1}\right)}$ describe the diffusions of $\overline{w^{\prime} w^{\prime}}$ in streamwise direction and $\overline{u^{\prime} u^{\prime}}$ in vertical direction respectively. Figure 6 shows the third order moments of velocity fluctuations $\left(M_{30}, M_{03}, M_{12}\right.$ and $\left.M_{21}\right)$ for both no seepage as well as seepage cases. The upstream free vegetation section has small positive values of $M_{30}$ and $M_{12}$ close to the bed and has negative values for $\mathrm{z} / \mathrm{H} \geq 0.06$ indicating the change in the transport of $\overline{u^{\prime} u^{\prime}}$-flux and $\overline{w^{\prime} w^{\prime}}$ diffusion of $M_{30}$ and $M_{12}$ to the streamwise direction. For the regions above $\mathrm{z} / \mathrm{H}=0.06$, the occurrence of $\overline{u^{\prime} u^{\prime}}$-flux and the $\overline{w^{\prime} w^{\prime}}$-diffusion opposite to the flow direction elevates as $\mathrm{z} / \mathrm{H}$ increases. The negative values of $M_{03}$ and $M_{21}(\mathrm{z} / \mathrm{H} \leq 0.06)$ and positive for $\mathrm{z} / \mathrm{H}>0.06$ suggests that the $\overline{w^{\prime} w^{\prime}}$-flux and the $\overline{u^{\prime} u^{\prime}}$-diffusion occur in vertically downward direction. For the centre of the vegetation zone, $M_{30}$ and $M_{12}$ have maximum positive values close to the top of the vegetation which modifies to negative values with increase in $z / H$. This implies that the $\overline{u^{\prime} u^{\prime}}$ flux and $\overline{w^{\prime} w^{\prime}}$ diffusion occurs in the streamwise direction for the vegetated layer and is opposite for the layer above the vegetation. The increase in the positive values of $M_{30}$ and $M_{12}$ near the bed is noted with increase in seepage percentage. The values of $M_{03}$ and $M_{21}$ have negative values near the bed, having maximum negative value close to the top of the vegetation, and have positive 
values for the region above the vegetation. This shows that that $\overline{w^{\prime} w^{\prime}}$ flux and $\overline{u^{\prime} u^{\prime}}$ diffusion occurs in the downward direction for the vegetated region. The application of downward seepage increases the negativity of $M_{03}$ and $M_{21}$.

[Insert Figure 6]

\section{Integral Scales of flow:}

The occurrence of turbulent sweep events in the region close to the bed develops coherent structures of the turbulent flow and affects the bed characteristics (Gyr and Schmid 1989). The modifications in time and length scales will provide information on the phenomenon of bed material transport in a vegetated channel. Integral scales are determined for the region at $\mathrm{z} / \mathrm{H}=0.11$ above the bed using the $120 \mathrm{~s}$ time series for both no seepage as well as seepage cases. An integral length scale shows the size of eddies generated in the flow and the turnover time for these eddies at a given point is defined by the time scale. The transfer of momentum and kinetic energy are done with the help of these eddies. The calculation of integral length and time scales are discussed in Devi and Kumar (2016b).

Insert table 2

\section{Insert Figure 7}

Integral time scale and length scale are shown in Table 2. $E_{T}$ and $E_{L}$ vary between 0.4181 $\mathrm{s}-0.7440 \mathrm{~s}$ and $0.0143-0.0947 \mathrm{~m}$ for no seepage, $0.5340-0.8820 \mathrm{~s}$ and $0.0211-0.1248 \mathrm{~m}$ for $10 \%$ seepage and $0.6279-0.9840 \mathrm{~s}$ and $0.0272-0.1399 \mathrm{~m}$ for $15 \%$ seepage. Figure 7 shows the variation $E_{T}$ and $E_{L}$ with flow depth for both no seepage and seepage cases. The occurrence of maximum values of length and time scales close to the top of the vegetation defines the region of maximum momentum exchange. As the percentage of 
downward seepage increases, integral length and time scales increase, highlighting the increase in momentum exchange and energy transfer. This shows that values of $E_{T}$ and $E_{L}$ elevate in seepage cases as compared to no seepage case. Thus, eddy length and eddy turnover time increase with increase in percentage of downward seepage. The increase in momentum exchange and energy transfer with increase in the percentage of seepage lead to occurrence of more turbulence resulting in an increase in Reynolds stress.

\section{Drag coefficient:}

The presence of vegetation in a channel increases the flow resistance, thereby helping in sediment deposition. There are a number of factors that affect the flow resistance in a vegetated channel like channel characteristics, vegetation characteristics and flow characteristics. Out of these factors, vegetation drag coefficient is regarded as the most important parameter to study the flow resistance in a vegetated channel (Stone and Shen 2002; Armanini et al 2005). The calculation for finding the drag coefficient can be found in Devi and Kumar (2016b).

\section{Insert Figure 8}

The values of $C_{D}$ for different seepage cases are shown in figure 8 . The values of drag coefficient change along the flow depth, having more value for the region closer to the bed and reduce with increase in $\mathrm{z} / \mathrm{H}$. The decrease in the rigidity and thickness of the plane with increase in $\mathrm{z} / \mathrm{H}$ leads to achievement of more drag coefficient closer to the bed. $C_{D}$ (no seepage) for the region close to bed has values $\leq 3$. The increase in the value of $C_{D}$ closer to the bed shows the dominance of the effect of viscosity (Nepf and Vivoni 2000). For the region close to the top of the vegetation, the form drag reduces which ultimately reduces the value of $C_{D}$. The change in the values of $C_{D}$ with the application of 
downward seepage is also observed. The average drag coefficient for no seepage is 2.30 , which reduces at 1.971 for $10 \%$ seepage and 1.631 for $15 \%$ seepage. This shows that $C_{D}$ decreases as the percentage of downward seepage elevates. It can be stated that downward seepage lessens the resistance offered by the vegetation.

\section{Conclusions}

An experimental study on a permeable channel covered fully with flexible rice stems has been investigated. Experiments were performed considering different percentage of downward seepage. Three measurement locations were selected (upstream freevegetation zone, centre of the vegetation zone and downstream free-vegetation zone) for exploring the change in flow conditions along the length of the channel. It is found that vegetation reduces the flow velocity in the vegetated region. The velocity close to the bed is elevated by $14 \%$ (average value) with $10 \%$ seepage and $20 \%$ (average value) with $15 \%$ seepage as compared to no seepage. The presence of vegetation still reduces the flow velocity even in seepage cases. The maximum value of Reynolds stress and turbulent intensity lie close to the vegetation top for vegetated region while for the upstream free vegetation zone, it lies close to the bed for both no seepage and seepage cases. On observing the magnitudes of Reynolds stress and turbulence intensities, the values in the vegetation zone is more because of the local erosion and deposition induced by vegetation stems. For both no seepage and seepage cases, vegetation reduces the Reynolds stress and turbulent intensities as the flow goes downstream. But an increase in Reynolds stress and turbulent intensities is observed as the percentage of seepage is increased. Moment analysis shows that the flux and diffusion along the flow direction and in vertically downward direction increase with increase in seepage percentage. An 
increase in the size of eddies and consequently the turnover time for eddies increases as the percentage of downward seepage elevates. Drag coefficient decreases with increase in the percentage of downward seepage.

\section{Acknowledgements}

Authors gratefully acknowledge PMAC, Ministry of Earth Sciences, Government of India sponsoring the project titled "Resistance Characteristics of mobile bed Vegetation (MOES/ PAMC/ H\&C I 26 I 20 13-PC-11)". The authors sincerely feel gratitude towards Sumit Kumar Mahto, Rishabh Daga, Bazal Hoque and Anurag Sharma for assisting in carrying out the experimental work.

\section{References}

Abt, S. R., Clary, W. P., \& Thornton, C. I. (1994). Sediment deposition and entrapment in vegetated streambeds. J. Irrig. Drain. Eng. 120(6): 1098-1111.

Bouma, T. J., Friedrichs, M., Van Wesenbeeck, B. K., Temmerman, S., Graf, G., \& Herman, P. M. J. 2009. Density $\square$ dependent linkage of scale $\square$ dependent feedbacks: A flume study on the intertidal macrophyte Spartina anglica. Oikos. 118(2):260-268. Braudrick, C. A., Dietrich, W. E., Leverich, G. T., \& Sklar, L. S. 2009. Experimental evidence for the conditions necessary to sustain meandering in coarse-bedded rivers. Proceedings of the National Academy of Sciences. 106(40): 16936-16941.

Cao, D., \& Chiew, Y. M. 2013. Suction effects on sediment transport in closed-conduit flows. J. Hydraul. Eng. 140(5): 04014008. 
Carollo, F. G., Ferro, V. I. T. O., \& Termini, D. 2005. Flow resistance law in channels with flexible submerged vegetation. J. Hydraul. Eng. 131(7):554-564.

Chao, W. A. N. G., YU, J. Y., WANG, P. F., \& GUO, P. C. 2009. Flow structure of partly vegetated open-channel flows with eelgrass. J. Hydrodyn. Ser. B. 21(3): 301-307.

Chen, X., \& Chiew, Y. M. 2004. Velocity distribution of turbulent open-channel flow with bed suction. J. Hydraul. Eng. 130(2): 140-148.

Chen, S. C., Kuo, Y. M., \& Li, Y. H. (2011). Flow characteristics within different configurations of submerged flexible vegetation. J. Hydrol. 398(1): 124-134.

Chen, Z., Ortiz, A., Zong, L., \& Nepf, H. (2012). The wake structure behind a porous obstruction and its implications for deposition near a finite patch of emergent vegetation. Water Resour. Res. 48(9).

Cotton, J. A., Wharton, G., Bass, J. A. B., Heppell, C. M., \& Wotton, R. S. (2006). The effects of seasonal changes to in-stream vegetation cover on patterns of flow and accumulation of sediment. Geomorphology. 77(3): 320-334.

Crowder, D. W., \& Diplas, P. (2002). Vorticity and circulation: spatial metrics for evaluating flow complexity in stream habitats. Can. J. Fish. Aquat.Sci. 59(4): 633-645.

Deshpande, V., \& Kumar, B. (2016). Advent of sheet flow in suction affected alluvial channels. Environ. Fluid Mech. 16(1): 25-44.

Deshpande, V., \& Kumar, B. (2016). Turbulent flow structures in alluvial channels with curved cross $\square$ sections under conditions of downward seepage. Earth Surf. Processes Landforms. 41: 1073-1087.

Devi, T. B., \& Kumar, B. (2015). Turbulent flow statistics of vegetative channel with seepage. J. Appl. Geophys. 123: 267-276. 
Devi, T. B., \& Kumar, B. (2016a). Experimentation on submerged flow over flexible vegetation patches with downward seepage. Ecol. Eng.91: 158-168.

Devi, T. B., \& Kumar, B. (2016b). Flow characteristics in an alluvial channel covered partially with submerged vegetation. Ecol. Eng. 94: 478-492.

Devi, T. B., Daga, R., Mahto, S. K., \& Kumar, B. (2016). Drag and Turbulent Characteristics of Mobile Bed Channel With Mixed Vegetation Densities Under Downward Seepage. J. Fluids Eng. 138(7): 071104.

Dey, S., Das, R., Gaudio, R., \& Bose, S. K. (2012). Turbulence in mobile-bed streams. Acta Geophys. 60(6): 1547-1588.

Finnigan, J. (2000). Turbulence in plant canopies. Annu. Rev. Fluid Mech. 32(1): 519571.

Finnigan, J. J., Shaw, R. H., \& Patton, E. G. (2009). Turbulence structure above a vegetation canopy. J. Fluid Mech. 637: 387-424.

Ghisalberti, M., \& Nepf, H. (2006). The structure of the shear layer in flows over rigid and flexible canopies. Environ. Fluid Mech. 6(3): 277-301.

Goring, D. G., \& Nikora, V. I. (2002). Despiking acoustic Doppler velocimeter data. J. Hydraul. Eng. 128(1): 117-126.

Gurnell, A. M., Van Oosterhout, M. P., De Vlieger, B., \& Goodson, J. M. (2006). Reach $\square$ scale interactions between aquatic plants and physical habitat: River Frome, Dorset. River Res. Appl. 22(6): 667-680.

Gyr, A., \& Schmid, A. (1989). The different ripple formation mechanism. J.Hydraul.Res. 27(1): 61-74. 
Järvelä, J. (2005). Effect of submerged flexible vegetation on flow structure and resistance. J. Hydrol. 307(1): 233-241.

Kemp, J. L., Harper, D. M., \& Crosa, G. A. (2000). The habitat-scale eco hydraulics of rivers. Ecol. Eng. 16(1): 17-29.

Kinzli, K. D., Martinez, M., Oad, R., Prior, A., \& Gensler, D. (2010). Using an ADCP to determine canal seepage loss in an irrigation district. Agric. Water Manage. 97(6): 801810.

Kouwen, N. N., \& Li, R. M. (1980). Biomechanics of vegetative channel linings. J. Hydraul. Div. 106(6): 1085-1103.

Kouwen, N., \& Unny, T. E. (1973). Flexible roughness in open channels. J. Hydraul. Div. 99(5): 713-728.

Li, S. S., \& Millar, R. G. (2011). A two $\square$ dimensional morphodynamic model of Gravel $\square$ bed River with floodplain vegetation. Earth Surf. Processes Landforms. 36(2): 190-202.

Li, Y., Wang, Y., Anim, D. O., Tang, C., Du, W., Ni, L., \& Acharya, K. (2014). Flow characteristics in different densities of submerged flexible vegetation from an openchannel flume study of artificial plants. Geomorphology. 204: 314-324.

Liu, D., Diplas, P., Fairbanks, J. D., \& Hodges, C. C. (2008). An experimental study of flow through rigid vegetation. J. Geophys. Res. Earth Surf. 113(F4).

López, F., \& García, M. (1998). Open $\square$ channel flow through simulated vegetation: Suspended sediment transport modeling. Water Resour. Res. 34(9):2341-2352.

Maclean, A. G. (1991). Open channel velocity profiles over a zone of rapid infiltration. J.Hydraul.Res. 29(1): 15-27. 
Martin, C. A., \& Gates, T. K. (2014). Uncertainty of canal seepage losses estimated using flowing water balance with acoustic Doppler devices. J. Hydrol. 517: 746-761.

Naden, P., Rameshwaran, P., Mountford, O., \& Robertson, C. (2006). The influence of macrophyte growth, typical of eutrophic conditions, on river flow velocities and turbulence production. Hydrol. Processes. 20(18): 3915-3938.

Nepf, H. M. (2012). Flow and transport in regions with aquatic vegetation. Annu. Rev. Fluid Mech. 44: 123-142.

Nepf, H. M. (1999). Drag, turbulence, and diffusion in flow through emergent vegetation. Water Resour. Res. 35(2):479-489.

Nezu, I., \& Sanjou, M. (2008). Turburence structure and coherent motion in vegetated canopy open-channel flows. J. Hydro-environ. Res.2(2): 62-90.

Okamoto, T. A., \& Nezu, I. (2009). Turbulence structure and "Monami" phenomena in flexible vegetated open-channel flows. J.Hydraul.Res. 47(6): 798-810.

Okamoto, T. A., \& Nezu, I. (2010). Flow resistance law in open-channel flows with rigid and flexible vegetation. River flow 2010, 261-268.

Patel, M., Deshpande, V., \& Kumar, B. (2015). Turbulent characteristics and evolution of sheet flow in an alluvial channel with downward seepage. Geomorphology. 248: 161171.

Poggi, D., Porporato, A., Ridolfi, L., Albertson, J. D., \& Katul, G. G. (2004). The effect of vegetation density on canopy sub-layer turbulence. Boundary-Layer Meteorol. 111(3): $565-587$.

Rao, A. R., \& Sitaram, N. (1999). Stability and mobility of sand-bed channels affected by seepage. J. Irrig. Drain. Eng. 125(6): 370-379. 
Raupach, M. R. (1981). Conditional statistics of Reynolds stress in rough-wall and smooth-wall turbulent boundary layers. J. Fluid Mech. 108: 363-382.

Richardson, J. R., Abt, S. R., \& Richardson, E. V. (1985). Inflow seepage influence on straight alluvial channels. J. Hydraul. Eng. 111(8): 1133-1147.

Righetti, M. (2008). Flow analysis in a channel with flexible vegetation using doubleaveraging method. Acta Geophys. 56(3): 801-823.

SANDJENSEN, K. A. J., \& VindbÆK Madsen, T. O. M. (1992). Patch dynamics of the stream macrophyte, Callitriche cophocarpa. Freshwater Biol. 27(2):277-282.

Schoelynck, J., De Groote, T., Bal, K., Vandenbruwaene, W., Meire, P., \& Temmerman, S. (2012). Self $\square$ organised patchiness and scale $\square$ dependent bio $\square$ geomorphic feedbacks in aquatic river vegetation. Ecography. 35(8):760-768.

Shaw, R. H. (1977). Secondary wind speed maxima inside plant canopies. J. Appl. Meteorol. 16(5):514-521.

Siniscalchi, F., Nikora, V. I., \& Aberle, J. (2012). Plant patch hydrodynamics in streams: Mean flow, turbulence, and drag forces. Water Resour. Res. 48(1).

Tanji, K. K., \& Kielen, N. C. (2002). Agricultural drainage water management in arid and semi-arid areas. FAO.

Temmerman, S., Bouma, T. J., Van de Koppel, J., Van der Wal, D., De Vries, M. B., \& Herman, P. M. J. (2007). Vegetation causes channel erosion in a tidal landscape. Geology. 35(7): 631-634.

Tennekes, H., \& Lumley, J. L. (1972). A first course in turbulence. MIT press.

Termini, D. (2015). Flexible vegetation behaviour and effects on flow conveyance: experimental observations. Int. J. Riv. Basin Manag., 13(4), 401-411. 
Wilcock, R. J., Champion, P. D., Nagels, J. W., \& Croker, G. F. (1999). The influence of aquatic macrophytes on the hydraulic and physico-chemical properties of a New Zealand lowland stream. Hydrobiologia. 416: 203-214.

Wilson, C. A. M. E., Stoesser, T., Bates, P. D., \& Pinzen, A. B. 2003. Open channel flow through different forms of submerged flexible vegetation. J. Hydraul. Eng. 129(11): 847853.

Yagci, O., \& Kabdasli, M. S. (2008). The impact of single natural vegetation elements on flow characteristics. Hydrol. Processes. 22(21): 4310-4321.

Yalin, M. S. (1972). Mechanics of sediment transport. Pergamon Press,Oxford,298

Zeng, C., \& Li, C. W. (2014). Measurements and modeling of open-channel flows with finite semi-rigid vegetation patches. Environ. Fluid Mech. 14(1): 113-134.

Zong, L., \& Nepf, H. (2012). Vortex development behind a finite porous obstruction in a channel. J. Fluid Mech. 691:368-391. 
Table 1 Uncertainty associated with ADV data

\begin{tabular}{|c|c|c|c|c|c|c|}
\hline & $\mathrm{U}$ & $\mathrm{V}$ & $\mathrm{W}$ & $\left.\overline{\left(u^{\prime} u^{7}\right.}\right)^{0.5}$ & $\left(\overline{v^{\prime} v^{7}}\right)^{0.5}$ & $\left(\overline{w^{\prime} w^{7}}\right)^{0.5}$ \\
\hline Standard & $4.34 \times 10^{-3}$ & $9.74 \times 10^{-4}$ & $4.24 \times 10^{-4}$ & $1.09 \times 10^{-3}$ & $9.04 \times 10^{-4}$ & $3.14 \times 10^{-4}$ \\
\hline deviation & & & & & & \\
\hline Uncertainty & 0.30 & 0.07 & 0.03 & 0.06 & 0.07 & 0.03 \\
\hline
\end{tabular}


Table 2 Integral time and length scales for no seepage, 10\% seepage and 15\% seepage

\begin{tabular}{|c|c|c|c|c|c|c|c|c|c|}
\hline \multirow[t]{2}{*}{ Location } & \multicolumn{3}{|c|}{ No Seepage } & \multicolumn{3}{|c|}{$10 \%$ Seepage } & \multicolumn{3}{|c|}{$15 \%$ Seepage } \\
\hline & $\begin{array}{c}U \\
(\mathrm{~m} / \mathrm{s})\end{array}$ & $\begin{array}{l}E_{T} \\
(s) \\
\end{array}$ & $\begin{array}{c}E_{L} \\
(m) \\
\end{array}$ & $\begin{array}{c}U \\
(\mathrm{~m} / \mathrm{s})\end{array}$ & $\begin{array}{l}E_{T} \\
(s) \\
\end{array}$ & $\begin{array}{c}E_{L} \\
(m) \\
\end{array}$ & $\begin{array}{c}U \\
(\mathrm{~m} / \mathrm{s})\end{array}$ & $\begin{array}{l}E_{T} \\
(s) \\
\end{array}$ & $\begin{array}{c}E_{L} \\
(m)\end{array}$ \\
\hline Upstream & 0.1736 & 0.5479 & 0.0947 & 0.1889 & 0.6605 & 0.1248 & 0.1941 & 0.7210 & 0.1399 \\
\hline Centre & 0.0244 & 0.7440 & 0.0181 & 0.044 & 0.8820 & 0.0388 & 0.0517 & 0.9840 & 0.0509 \\
\hline Downstream & 0.0344 & 0.4181 & 0.0143 & 0.0396 & 0.5340 & 0.0211 & 0.0433 & 0.6279 & 0.0272 \\
\hline
\end{tabular}


Figure 1 (a) Schematic diagram of the tilting flume with magnified plan view of test section (b) Photograph taken after placing vegetation (c) Photograph showing the measurement location

Figure 2 Velocity distribution at the free upstream showing the fit of logarithmic law

Figure 3 Velocity distribution at the upstream, centre and downstream of vegetation section for no seepage,10\% seepage and $15 \%$ seepage (Dashed line shows the top of vegetation)

Figure 4 Reynolds stress distribution at the upstream, centre and downstream of vegetation section for no seepage,10\% seepage and $15 \%$ seepage

Figure 5 RMS of turbulent fluctuations at the upstream, centre and downstream of vegetation section for no seepage, $10 \%$ seepage and $15 \%$ seepage

Figure 6 Third order moments distribution at the upstream, centre and downstream of vegetation section for no seepage, $10 \%$ seepage and $15 \%$ seepage

Figure 7 Time and Length scales plotted against the flow depth for the centre of the vegetation zone

Figure 8 Drag coefficient for the centre of the vegetation zone 
(a)
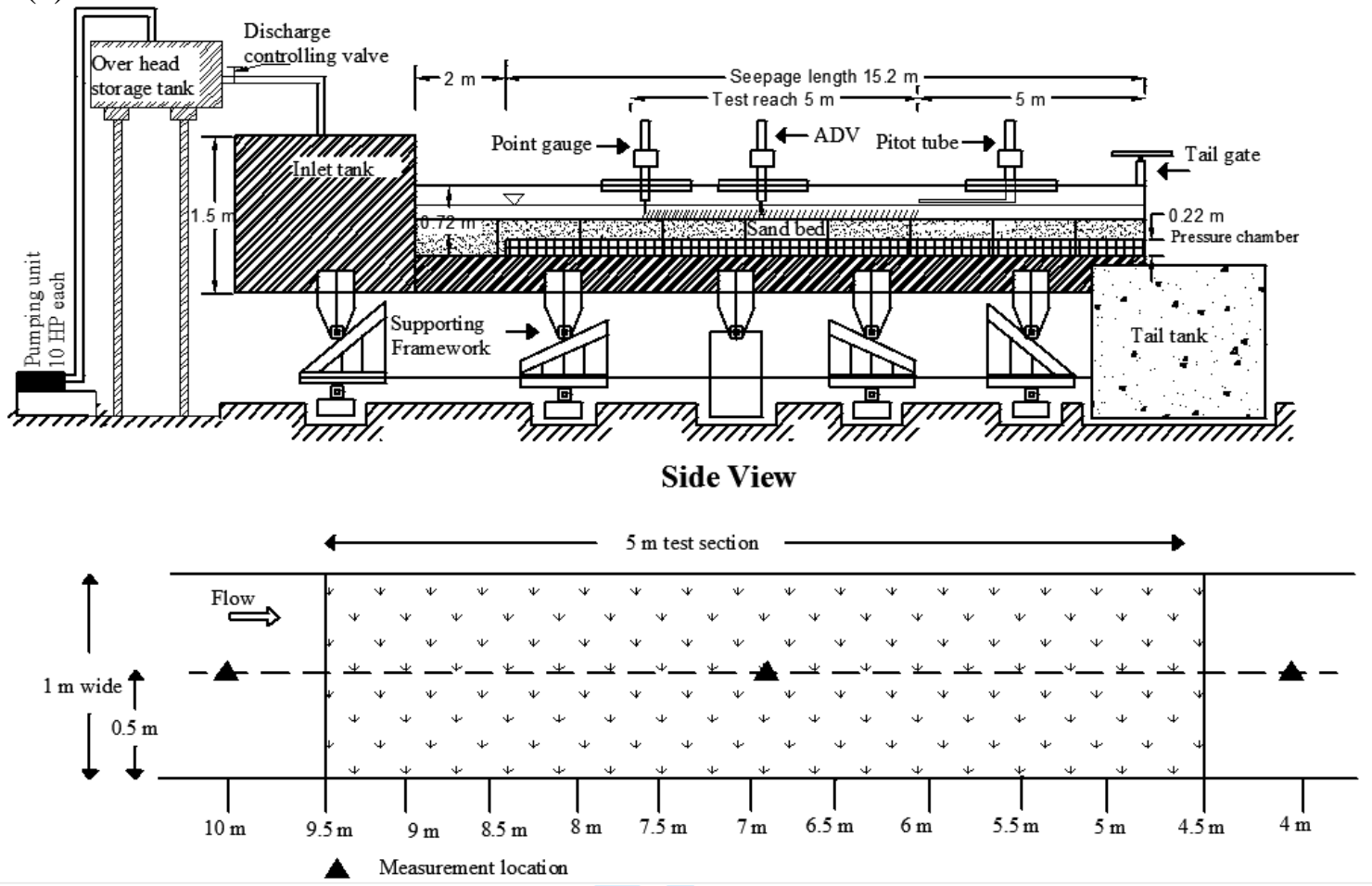

(b)

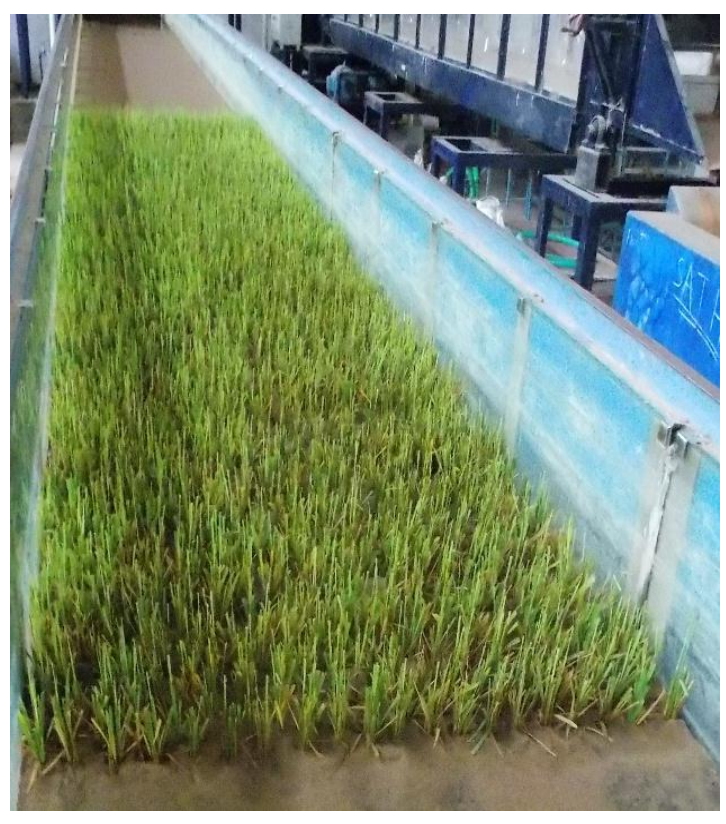

(c)

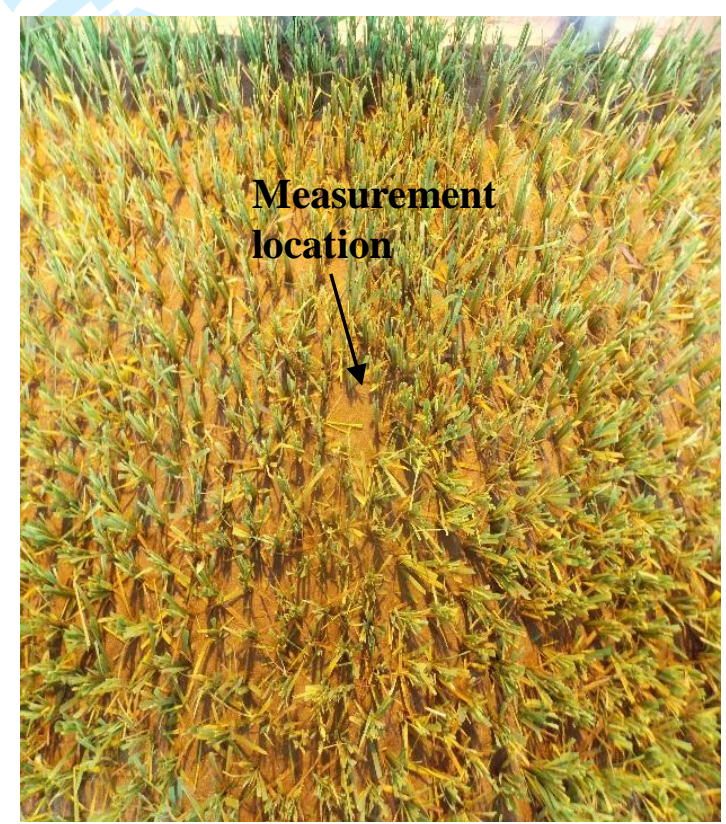




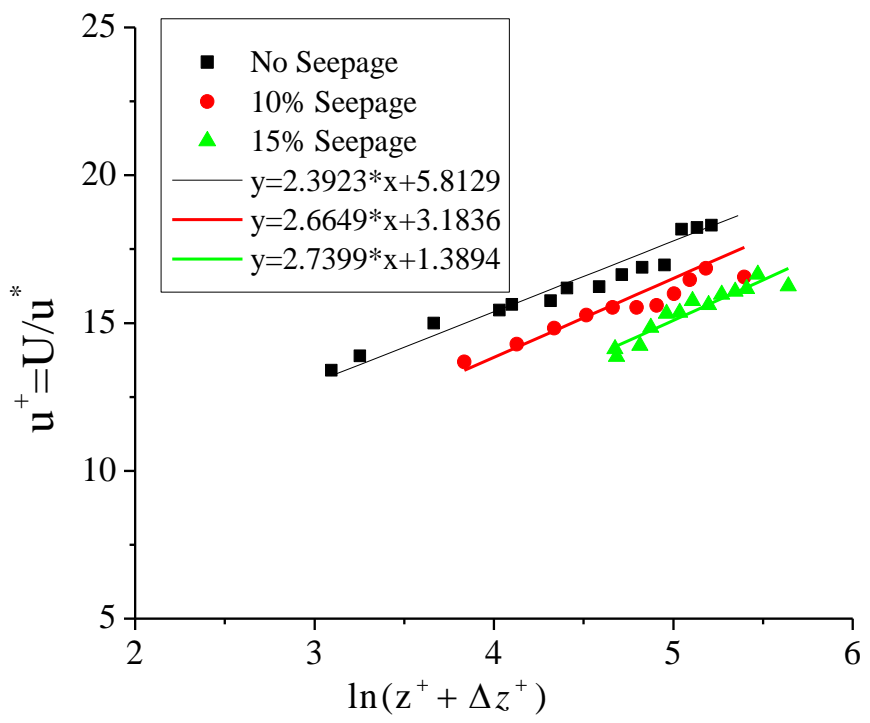

https://mc06.manuscriptcentral.com/cjce-pubs 


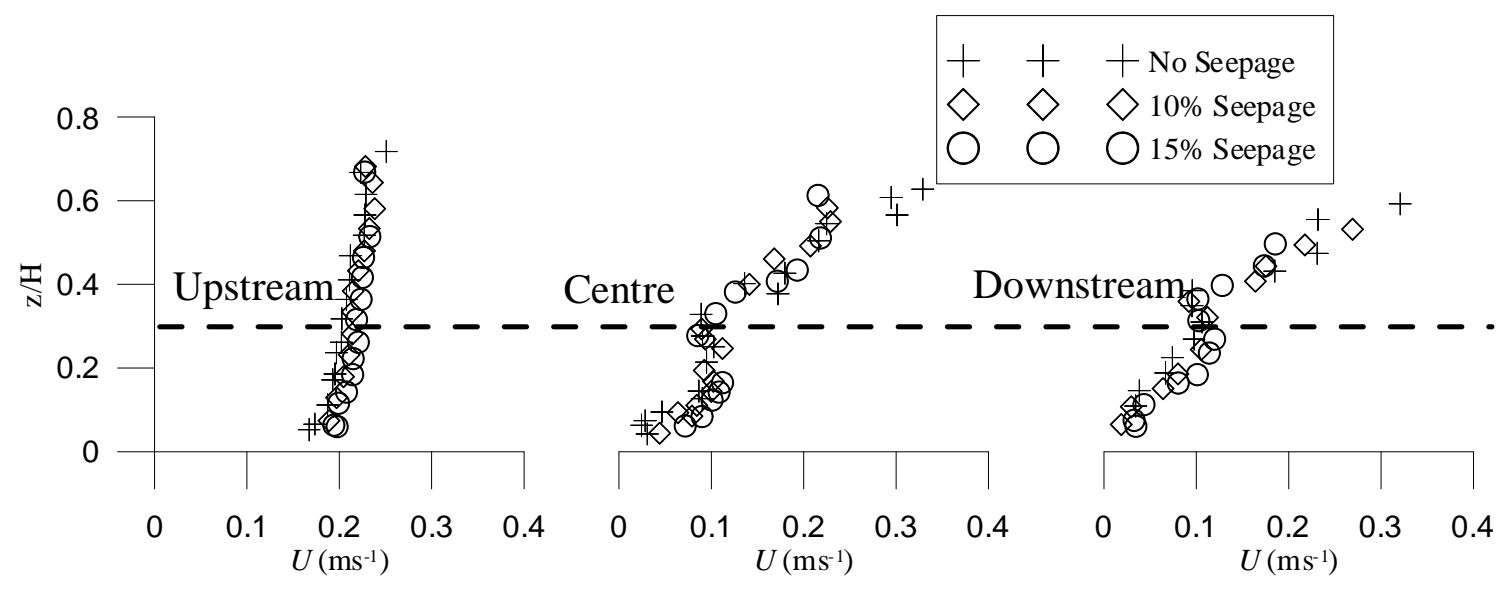




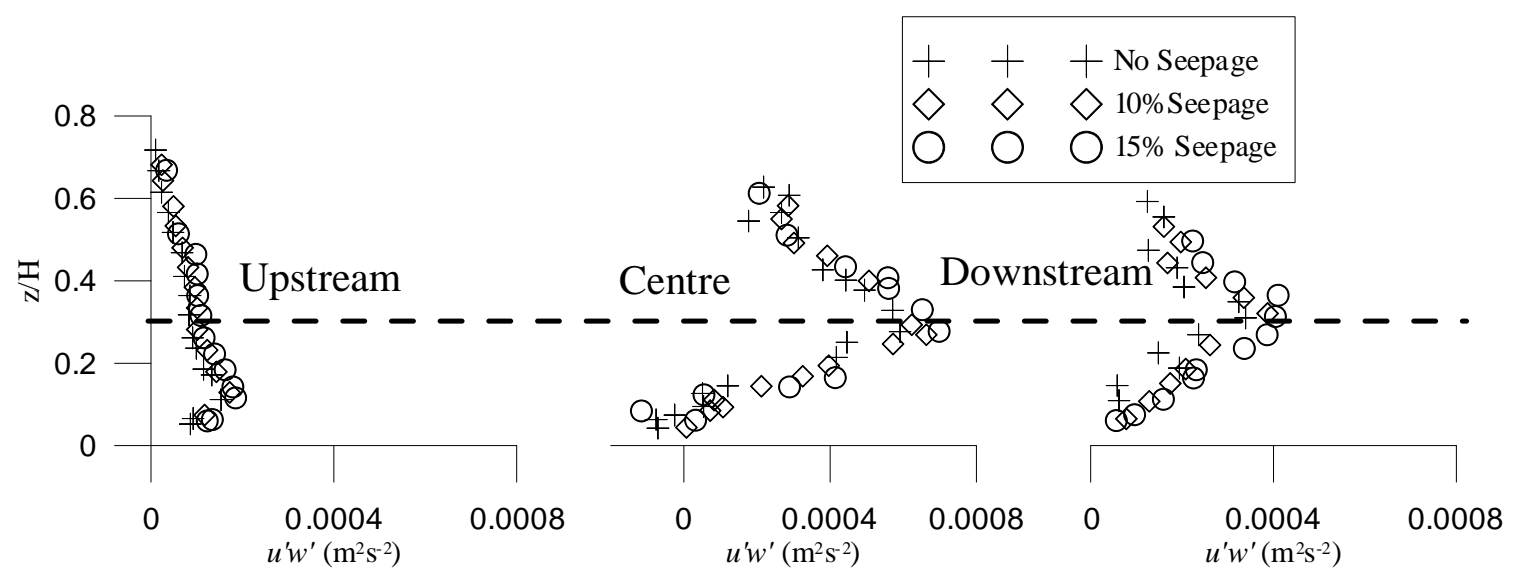



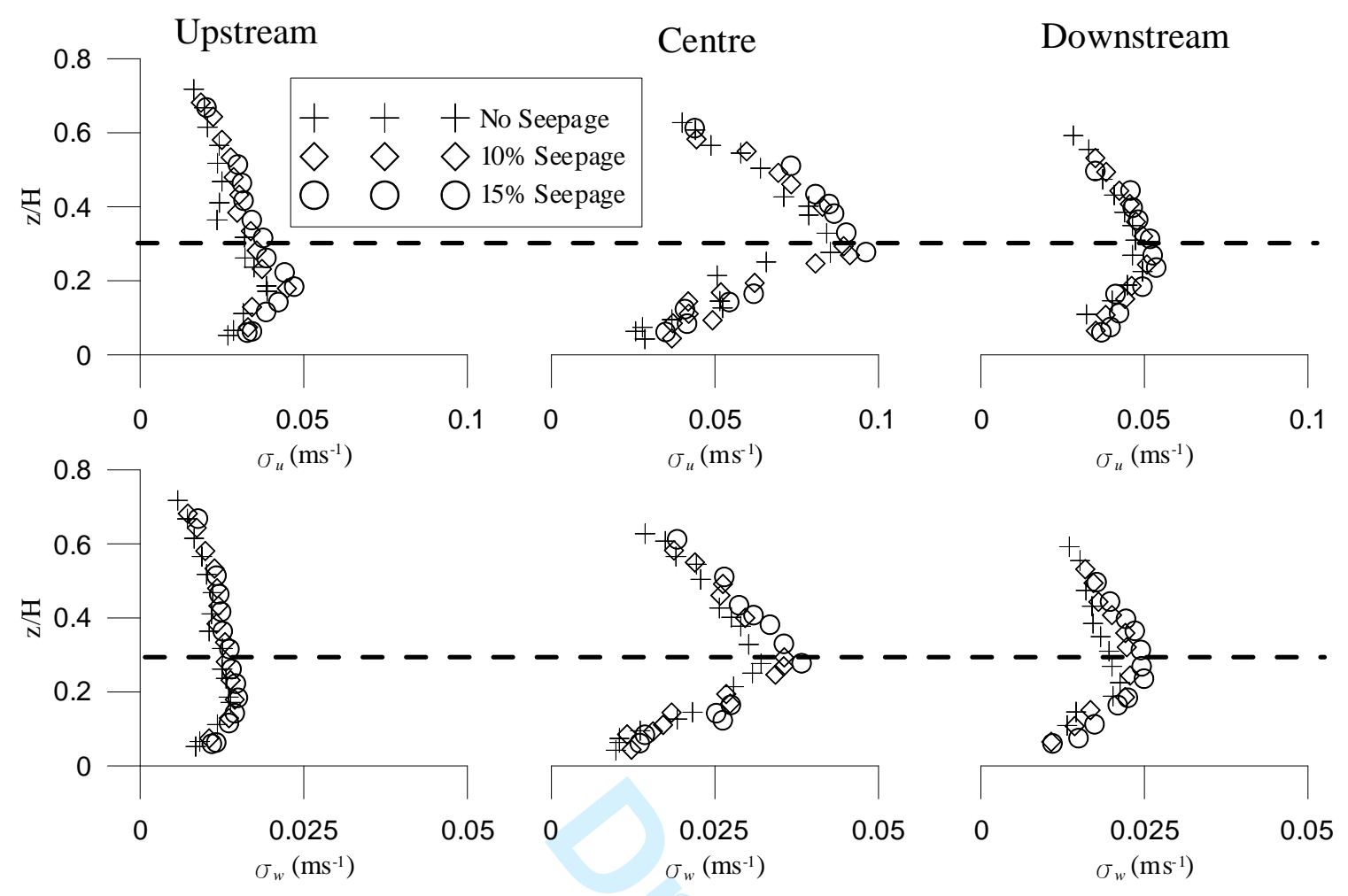

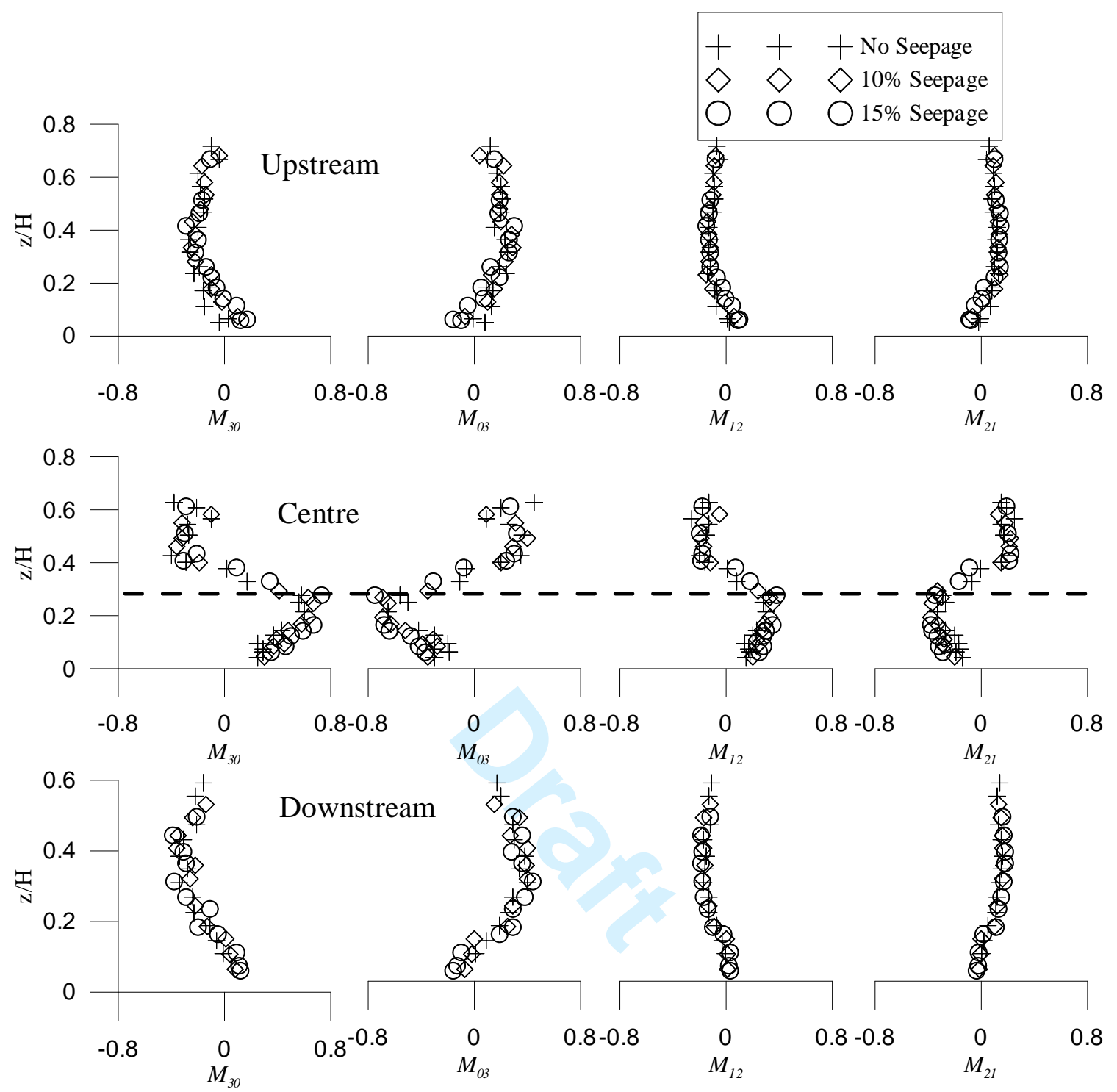


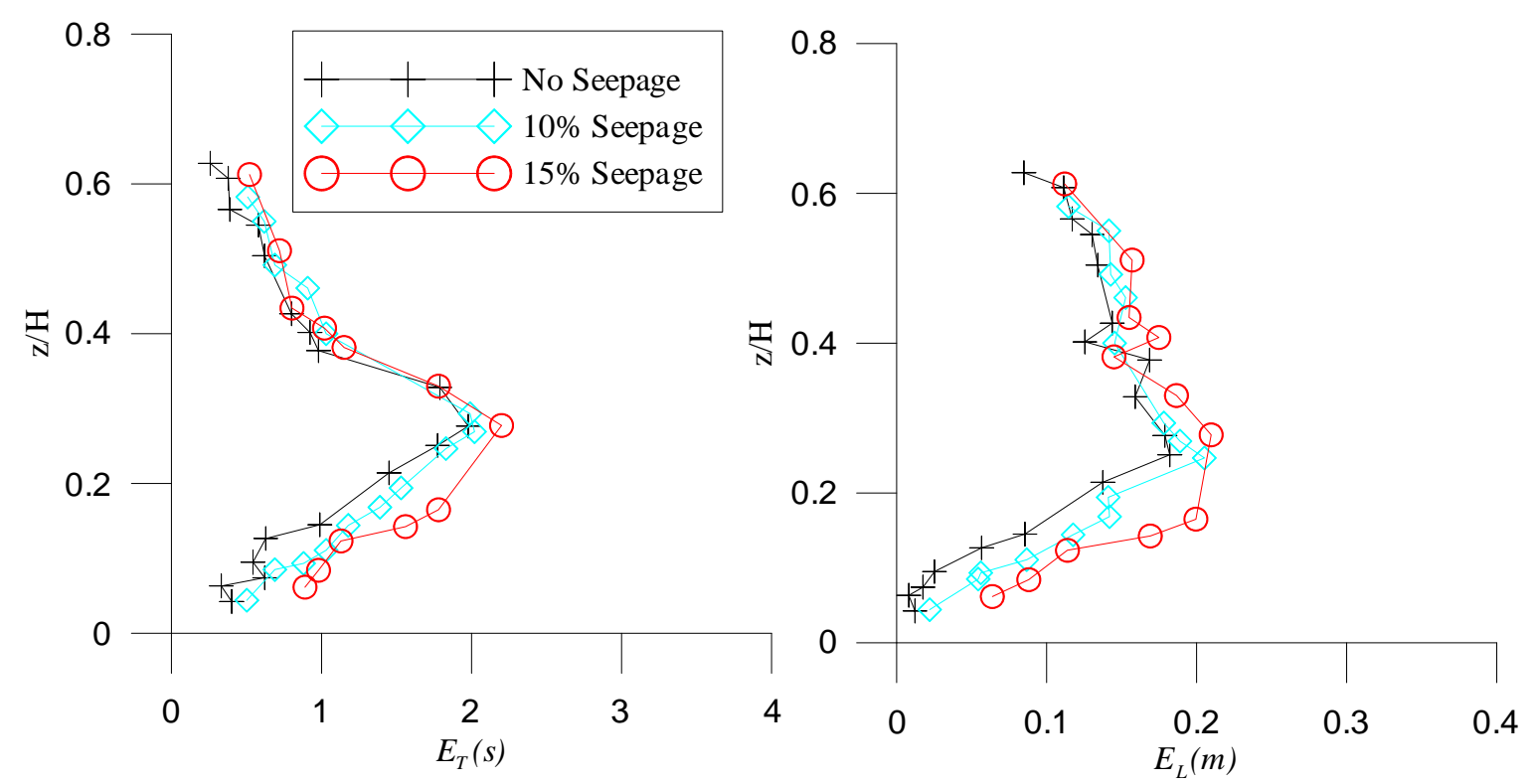




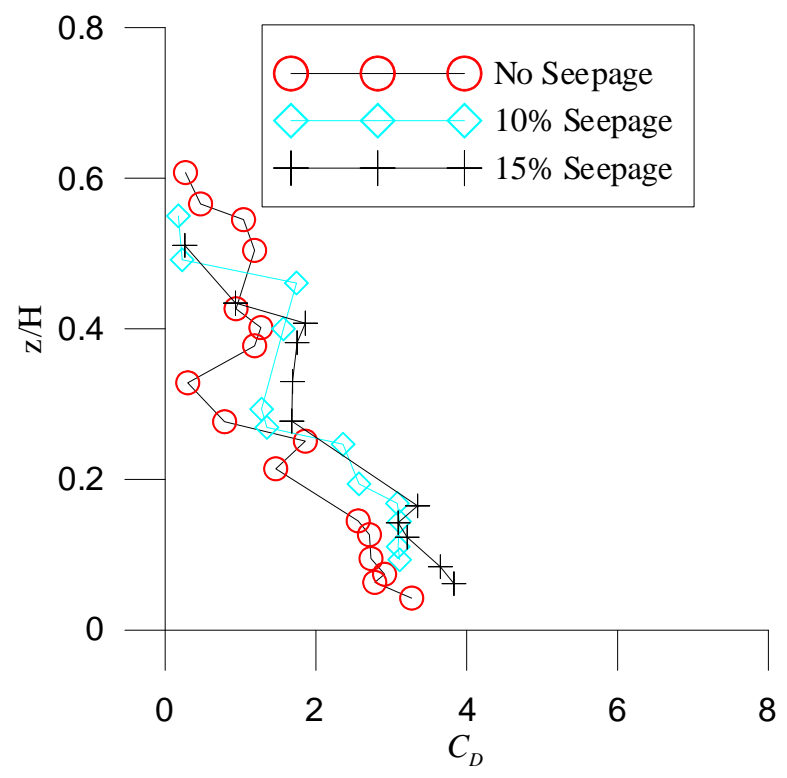

https://mc06.manuscriptcentral.com/cjce-pubs 